\title{
Analysis of Intention to Continue Services Among Recruited Voluntary Soldiers
}

\author{
Kuo-Wei Lin, Chia-Mu Kuan and Chi-Hao Lu \\ Department of International Business, \\ Hsuan Chuang University Hsinchu, Taiwan 30092, R.O.C., Taiwan
}

\begin{abstract}
In order to attract more promising young people to join the military and enhance combat capability, Taiwan's Department of Defense is transforming the nation's military service system from a draft system, which has been in effect for more than sixty years, to an all-volunteer military force system. The government hopes that the new system not only can recruit promising voluntary soldiers, but that they also continue their military service after the contract expires in order to ensure stability in recruitment sources. This study explores the intention of voluntary soldiers to continue their military service. This study's questionnaire encompasses five dimensions: Participation motivation, organization commitment, career planning, personality traits and departure tendency. The questionnaires were issued to 350 voluntary soldiers to explore if they intend to continue their service after their contract expires, with a total of 314 effective questionnaires that were recovered and analyzed. The results find that about half of the voluntary soldiers indicate that they do not plan on staying and continuing their service after contract expiration, which will result in understaffing in the military. In order to stabilize the prescribed number of soldiers, the existing recruiting policy and military management system should be re-adjusted.
\end{abstract}

Keywords: Participation Motivation, Organizational Commitment, Career Planning, Personality Traits, Departure Tendency, Recruit, Voluntary Service

\section{INTRODUCTION}

Coupled with the global trend and in response to public calls for reducing the length of service under the conscription system, Taiwan's Department of Defense in 2003 selected three experimental battalions to implement an mercenary system. However, due to the rapidly changing modern warfare and the constant modernization and enhancement of the quality and quantity of weapons and equipment, Liu et al. (2011) questioned the professional quality of soldiers who have to operate modern equipment after the implementation of weapons' modernization and whether their experiences can be transferd on and continued. Because both are very important issues when considering to implement an allvolunteer system, this study focuses on exploring whether recruited voluntary soldiers have the intention to continue their services and transfer on their experiences, or refuse to continue their services and cause understaffing and disruptions in experience for the military. This study explores separetly the reasons why voluntary soldiers decide to continue their services or retire from the military. The results offer a useful reference for human resource departments in military strength buildup and war preparation.

\section{MATERIALS AND METHODS}

The results and effectiveness of recruiting voluntary soldiers in Taiwan are impacted by the current social environment, traditional values and the military's strategy for recruitment. In exploring the military's strategy for recruitment, $\mathrm{Wu}$ (2010) found three important reasons for young people to join the armed

Corresponding Author: Kuo-Wei Lin, Department of International Business, Hsuan Chuang University Hsinchu, Taiwan 30092, R.O.C., Taiwan 
forces: Good salary (67.4\%), stable work (64.6\%) and excellent welfare benefits (48.6\%). Liang et al. (2008) stressed that except for treatment, young people also emphasized work values, work satisfaction and work performance that affect voluntary soldiers' intention to continue their services. Liu and Peng (2011) argued in exploring the future trend of a mercenary system that despite the fact voluntary soldiers hope to receive stable regular income, they are also eager to learn professional skills to prepare themselves after retiring from the military services to work again in society. In summarizing the aforementioned viewpoints, this study explores five dimensions of voluntary soldiers' intention to continue their services after the contracted service period expires: Participation motivation, organizational commitment, career planning, personality traits and turnover tendency.

\subsection{Participation Motivation}

Herbert (1976) argued that motivation is the progress that enables a person to complete a work. In other words, motivation may prompt a person to strive in achieving a goal. Maslow (1943) focused on the theory of motivation and concluded that human beings may gradually enhance their level of needs after an increase in income and for older ages, which starts from satisfying physiological demands and then moves on to satisfying their needs for security, integrating into society, being respected and achieving self-realization. In exploring organizational behaviors, Herzberg et al. (1993) concluded that employees might be affected by two factors-Hygiene Factor and Motivator Factor-that might determine employees' work attitude and performance in the organization. Alderfer (1972) revised Maslow' needhierarchy theory and simplified the five needs into three motives of needs: Existence, relatedness and growth, which is also called the ERG Theory.

\subsection{Organizational Commitment}

The term "organizational commitment" was first introduced by Whyte (1956). Sheldon (1971) then defined organizational commitment as a linked and consistent attitude or inclination between individuals and organization. Hrebiniak and Alutto (1973) supplemented that organizational commitment is the behavioral inclination of members who do not intend to leave the organization due to salary, position, freedom of professional creation and friendship among colleagues. In investigating the relationship between employees and organization, Mowday (1982) found that organizational commitment represents employees' identification with the organization and the intensity of employees' willingness to work hard for the organization and thus organizational commitment should include three dimensions: value commitment, effort commitment and retention commitment.

\subsection{Personality Traits}

Personality refers to people's inner psychological characteristics that show an individual's response to an external environment. Revelle (1995) thus stressed that personality traits are one's characteristics or nature that are different from others'. Such traits are considered as the basic unit of a personality, reflect the inner inclination of individual behaviors through a specific way and are durable and stable to some extent. In exploring organizational management, Huang and Yan (2010) called for an emphasis on employees' two personality traits of internal control and external control, because employees who have an internal locus of control or believe success comes from working hard and failure is a personal responsibility will work hard and shoulder more responsibility. Employees who have an external locus of control do not believe there is relationship between success (or failure) and working hard and thus they will not work hard and shoulder any responsibility.

\subsection{Career Planning}

Super (1976) defined a career as the course and progress of the evolution of various events, including the roles played by everybody in the workplace in their life. Derr (1986) argued that when discussing a career, one's individual life should be respected. He investigated 150 military personnel who have the potential to be promoted as generals and found that some of them were eager to be promoted as generals while others had no interest in the promotion. Thus, Derr (1986) presented that everyone's career inclination should be respected. He also promoted an individual's career development inclinations into emphasizing promotion, stability, freedom, challenge and balance.

\subsection{Departure Tendency}

Tett and Meyer (1993) found that departure tendency might generate a strong cognition before the departure. Chen and Lo (2005) also noted that when there is a gap between the role played by soldiers and their career expectation, they are prone to a strong departure tendency that results in a passive work attitude. Hence, we should pay special attention to the effects of departure tendency on the combat capability of armed forces. If we can control soldiers' departure tendency in 
advance, then it certainly is very helpful for the planning of human resources in the military.

In summarizing the aforesaid concepts, this study conducts the following five hypotheses:

- Hypothesis 1: Explore the effects of participation motivation on organizational commitment

- Hypothesis 2: Explore the effects of organizational commitment on career development

- Hypothesis 3: Explore the effects of career development on departure tendency

- Hypothesis 4: Explore organizational commitment after the adjustment of personality traits on career development

- Hypothesis 5: Explore the effects of participation motivation on departure tendency

\section{RESULTS AND DISCUSSION}

With voluntary soldiers at Air Force and Army bases in Northern Taiwan as subjects, a total of 350 questionnaires were issued and 320 of them were recovered. After scrapping six ineffective questionnaires that contained incomplete answers, this study has 314 effective recovered questionnaires, for a recovery rate of $89.7 \%$. In the study employs SPSS software as an analytic tool to verify the relationship of structure and variables. The level of significance in the various statistics is set at $\alpha=0.05$.

\subsection{Analyses of Correlations between Participation Motivation and Organization Commitment}

The results show that there is a significant positive correlation $(\mathrm{r}=0.733, \mathrm{p}<0.01)$ between overall participation motivation and organizational commitment. This means the stronger the participation motivation is that is felt by the voluntary soldiers, the stronger the response will be to organizational commitment, as Table 1 shows.

\subsection{Analyses of Correlations between Organizational Commitment and Career Development}

The results show that there is a significant positive correlation $(\mathrm{r}=0.287, \mathrm{p}<0.01)$ between organizational commitment and career planning. In other words, the higher organizational commitment is the more stable the voluntary (reserve) soldiers' career planning will be.

\subsection{Analyses of Correlations between Career Development and Departure Tendency}

The results show that there is a significant positive correlation $(\mathrm{r}=0.221, \mathrm{p}<0.01)$ between career development and departure tendency. The more perfect the voluntary (reserve) soldiers' planning career development is, the stronger the response will be to departure tendency, as Table 2 shows.

\subsection{Interactive Effects of two Sub-Dimensions of Personality Traits on the Adjustment of Organizational Commitment and Career Development}

Baron and Kenny (1986) argued that the effects of adjustment is the third independent variable of the characteristic of independence and proved that it greatly affects dependent variable after intervening in the original model. In order to get rid of the effects of different samples on the explanatory capability of dependent variable, we take service, age, rank and seniority as control variables and input the variables of the dimensions of organizational commitment and personality traits and the interaction between dimensions of organizational commitment and personality traits into hierarchical regression analyses as variables. Table 3 re-organizes and compiles the effects of adjustment.

Table 1. Analysis of correlations between participation motivation and each variable

\begin{tabular}{|c|c|c|c|c|}
\hline Variable & $\begin{array}{l}\text { Effort } \\
\text { commitment }\end{array}$ & $\begin{array}{l}\text { Value } \\
\text { commitment }\end{array}$ & $\begin{array}{l}\text { Retention } \\
\text { commitment }\end{array}$ & $\begin{array}{l}\text { Overall } \\
\text { organizational } \\
\text { commitment }\end{array}$ \\
\hline Compensation & $0.621^{* *}$ & $0.611^{* *}$ & $0.424^{* *}$ & $0.642^{* *}$ \\
\hline Work environment & $0.490^{* *}$ & $0.472^{* *}$ & $0.362^{* *}$ & $0.514^{* *}$ \\
\hline Sense of identification & $0.718^{* *}$ & $0.691^{* *}$ & $0.369^{* *}$ & $0.698^{* *}$ \\
\hline Sense of responsibility & $0.678^{* *}$ & $0.630^{* *}$ & $0.358^{* *}$ & $0.645^{* *}$ \\
\hline Overall participation motivation & $0.739^{* *}$ & $0.707^{* *}$ & $0.447^{* *}$ & $0.733^{* *}$ \\
\hline
\end{tabular}

Note: $\mathrm{n}=314,{ }^{*} \mathrm{p}<0.05,{ }^{* *} \mathrm{p}<0.01,{ }^{* * *} \mathrm{p}<0.001$. 
Table 2. Analyses of correlations between career development and departure tendency

\begin{tabular}{|c|c|c|c|c|c|c|}
\hline $\begin{array}{l}\text { Variable } \\
\text { Development }\end{array}$ & Job security & Challenge & Stability & Independence & Start a business & Career \\
\hline Challenge & $0.667^{* *}$ & & & & & \\
\hline Stability & 0.021 & -0.002 & & & & \\
\hline Independence & $0.249^{* *}$ & 0.104 & $0.339^{* *}$ & & & \\
\hline Start a business & $0.470^{* *}$ & $0.494^{* *}$ & 0.057 & $0.324^{* *}$ & & \\
\hline Career development & $0.736^{* *}$ & $0.628^{* *}$ & $0.540^{* *}$ & $0.614^{* *}$ & $0.680^{* *}$ & \\
\hline Departure tendency & $-0.190^{* *}$ & $0.236^{* *}$ & $-0.196^{* *}$ & -0.093 & $0.135^{*}$ & $0.221^{* *}$ \\
\hline
\end{tabular}

Note: $\mathrm{n}=314, * \mathrm{P}<0.05, * * \mathrm{P}<0.01, * * * \mathrm{P}<0.001$.

Table 3. The effects of adjustment of two dimensions of personality trait

\begin{tabular}{|c|c|c|c|c|c|}
\hline \multirow[b]{2}{*}{ Variable } & \multicolumn{5}{|c|}{ Career development } \\
\hline & Model $1 \beta$ & Model $2 \beta$ & Model $3 \beta$ & Model $4 \beta$ & Model $5 \beta$ \\
\hline 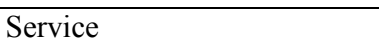 & $0.231^{* * *}$ & $0.203^{* * *}$ & $0.191^{* *}$ & $0.209^{* * * *}$ & $0.209^{* * * *}$ \\
\hline Age & -0.005 & -0.028 & -0.030 & -0.035 & -0.032 \\
\hline Rank & -0.073 & -0.097 & -0.099 & -0.092 & -0.086 \\
\hline Seniority & -0.142 & -0.036 & -0.116 & -0.031 & -0.073 \\
\hline Organizational Commitment & & $0.540^{* * *}$ & & $0.519^{* * *}$ & $0.280^{* *}$ \\
\hline Internal Control & & & $0.273^{* * *}$ & 0.061 & -0.140 \\
\hline External Control & & & $-0.108^{*}$ & $-0.133^{* *}$ & -0.280 \\
\hline $\begin{array}{l}\text { Organizational Commitment } \\
\times \text { Internal Control }\end{array}$ & & & & & 0.293 \\
\hline $\begin{array}{l}\text { Organizational Commitment } \\
\times \text { External Control }\end{array}$ & & & & & 0.233 \\
\hline $\mathrm{R}^{2}$ & 0.081 & 0.363 & 0.165 & 0.348 & 0.400 \\
\hline $\operatorname{Adj}^{2}$ & 0.063 & 0.349 & 0.143 & 0.366 & 0.448 \\
\hline $\mathrm{F}$ & $4.498^{* * *}$ & $24.926^{* * *}$ & $7.574^{* * *}$ & $21.060^{* * *}$ & $200.016^{* * *}$ \\
\hline
\end{tabular}

Note: $\mathrm{n}=314,{ }^{*} \mathrm{p}<0.05,{ }^{* *} \mathrm{p}<0.01,{ }^{* * *} \mathrm{p}<0.001$

From model 2 in Table 3, the control variable and organizational commitment are obtained as independent variables. After the adjustment of the model's explanatory capability, $\mathrm{R}^{2}$ is $0.349(\mathrm{p}<0.001)$ and reaches the level of significance. We see that organizational commitment significantly affects career development $(\beta$ $=0.540, \mathrm{p}=<0.001)$, meaning that the higher the voluntary soldiers' satisfaction with work and organizational commitment is, the lower their career development planning will be. In regression model 3, with two dimensions of control variable and personality traits as the prediction variables, after the adjustment of model $3, \mathrm{R}^{2}$ is $0.143(\mathrm{p}<0.001)$ and reaches the level of significance. This means that if the voluntary soldiers have personality traits of internal control tendency, then these personality traits have considerable effects on career planning. In regression model 4, with two dimensions of organizational commitment and personality traits as prediction variables, after the adjustment of the model's explanatory capability, $\mathrm{R}^{2}$ is $0.366(p<0.001)$ and reaches the level of significance. In model 5 the regression analyzes the interaction of the effects of adjustment. From the results, we learn that the effects of adjustment of two dimensions of personality traits are not significantly correlated.

\subsection{Analyses of Correlations between Organizational Commitment and Participation Motivation}

The results show that there is significant positive correlation $(\mathrm{r}=0.700, \mathrm{p}<0.01)$ between overall organizational commitment and participation motivation. This means that the stronger voluntary soldiers' motivation to join armed forces is the stronger military organizational commitment will be.

\section{CONCLUSION}

This study's results present that in the four dimensions of participation motivation, the respondents pay more attention to stable work under 
long-term employment and a secure environment. The three dimensions of organizational commitment show that the respondents pay more attention to the nature of work and the preference of work. The five dimensions of organizational commitment reflect that the respondents hope they can work in an environment with job security and a job rotation system. The two dimensions of personality traits present that the respondents prefer to work in an environment that they can control by themselves. The part of departure tendency shows that nearly half of respondents have a high intention to leave the job. We believe that they have not adjusted themselves well to the current military policy and regulation system and such a phenomenon is worth being alerted to.

After investigating the adjustment effects of the two sub-dimensions of personality trait variables on organizational commitment and career development tendency, we find that the adjustment effects of two sub-dimensions of personality traits are not significantly correlated. In the regression models of departure tendency and control variable, we note that the higher voluntary soldiers' participation motivation is, the higher departure intention will be. However, high-tech weapons and equipments need professional personnel to operate them. If the military cannot retain professional soldiers, then the use and maintenance of such weapons will be compromised and operation missions will be negatively affected. The authorities should pay much more attention to such results.

\subsection{Recommendation}

In synthesizing the above results, this study makes the following four recommendations for enhancing the proportion of voluntary soldiers who wish to continue their military service in order to ensure stability in recruitment sources.

\subsection{Enhance the Quality of Voluntary Soldiers}

The main purpose of an all-volunteer system is to recruit medium and long-term voluntary soldiers through longer professional training and service periods, so that the troops' professional capability can be maintained. In light of the current rapid changes in technology and the emergence of more advanced weaponry, the military needs high-quality soldiers to maximize the system's effectiveness. The priority in expanding the recruitment of voluntary soldiers should focus on quality. In the past, recruitment focused on a dramatic increase in quantity and neglected the enhancement of quality. As a result, some of the recruited personnel are not qualified enough, hindering the operation of military affairs.

\subsection{Promises Made in Recruitment MUST be Fulfilled}

The results herein show that among voluntary soldiers' motives for joining the armed forces, a sense of identification has the best predictability and explanatory capability. If promises made in recruitment are actually realized, then soldiers would feel that the unit he or she serves is a good workplace and they would be proud of that unit and willing to continue their service. However, if promises are not fulfilled, then soldiers would feel they were cheated, thus affecting their sense of identification and work attitude toward the military. Therefore, before recruiting voluntary soldiers, the authorities should carefully assess the adequacy and feasibility of their recruitment propaganda and should not make promises that are impossible to realize or depict fantastic visions that do not match reality.

\subsection{Be Familiarized with Voluntary Soldiers' Personality Traits}

The higher employees' internal control tendency is, the stronger their organizational commitment will be, because the employees who have internal control and who are retained in the organization are often the ones who have higher commitments to the organization. However, in Taiwan's current military, education is the only consideration for promotion, as the factor of personality traits is neglected. If a leading cadre cannot give subordinates different incentives and missions according to their personality traits and positioning, then it will be impossible to shape the military soldier's characteristics of sacrifice and dedication and sense of mission.

\subsection{Create a Learning Organization}

Impacted by social changes and military professionalization, the learning and training that soldiers receive cannot satisfy practical needs any more. Therefore, the military should assist and encourage soldiers to participate in off-work study and training for the obtainment of licenses, should constantly implement a life-long learning education and can even cooperate with universities in which professors teach various technical and vocational courses on the military base at night. This would certainly help voluntary soldiers enhance their professional capability. 


\section{REFERENCES}

Alderfer, C.P., 1972. Existence, Relatedness and Growth: Human Needs in Organizational Settings. 1st Edn., University of California, London, pp: 198.

Baron, R.M. and D.A. Kenny, 1986. The moderatormediator variable distinction in social psychological research: Conceptual, strategic and statistical considerations. J. Personality Soc. Psychol., 51: 1173-1182. DOI: 10.1037/0022-3514.51.6.1173

Chen, L.J. and H.H. Lo, 2005. The relationship among soldiers' role definition, career expectable gap and job attitudes: The difference between voluntary officers and reserve officers. J. National Defense Manage., 26: 85-100.

Derr, C.B., 1986. Managing the New Careerists. 1st Edn., Jossey-Bass Inc Publication, San Francisco, ISBN-10: 0875896774, pp: 288.

Herbert, T.T., 1976. Dimensions of Organizational Behavior. 1st Edn., Collier Macmillian, New York, ISBN-10: 0023537205, pp: 530.

Herzberg, F., B. Mausner and B.B. Synderman, 1993. The Motivation to Work. 1st Edn., Transaction Publishers, New Brunswick, ISBN-10: $156000634 X$, pp: 157.

Hrebiniak, L.G. and J.A. Aluttto, 1973. Personal and role-related factors in the development of organizational commitment. Admin. Sci. Q., 17: 555-573.

Huang, Y.L. and Y. Yan, 2010. Locus of control: Literature review and its application to management. Chin. J. Manage., 7: 111-117.

Liang, J.H., S.C. Su and T.F. Liao, 2008. The study relationship among work value, work satisfaction and work performance in military volunteer soldiers-the case of service support in northern area. J. Chin. Trend Forward, 4: 1-23.
Liu, Y.W. and Z.H. Peng, 2011. A study on the future development of mercenary system in Taiwan-with voluntary soldiers as an example. Air Force Bimonthly J., 619: 119-129.

Liu, Z.J., Y. Liu and C.H. Wu, 2011. Apply GM $(1,1)$ to forecast the future manpower supply and demand of roc male volunteer soldier. J. National Defense Manage., 32: 27-37.

Maslow, A.H., 1943. A theory of human motivation. Psychol. Rev., 50: 370-396. DOI: 10.1037/h0054346

Mowday, R.T., 1982. Employee-Organization Linkages: the Psychology of Commitment, Absenteeism and Turnover. 1st Edn., Academic Press, New York, ISBN-10: 0125093705, pp: 253.

Revelle, W., 1995. Personality processes. Annual Rev. Psychol., 46: 295-323. DOI: 10.1146/annurev.ps.46.020195.001455

Sheldon, M.E., 1971. Investments and involvements as mechanisms producing commitment to the organization. Admin. Sci. Q., 16: 143-150.

Super, D.E., 1976. Career education and the meanings of work. Monographs on career education. U.S. Government Printing Office, Washington, D.C.

Tett, R.P. and J.P. Meyer, 1993. Job satisfaction, organizational commitment, turnover intention and turnover: Path analyses based on meta-analytic findings. Personnel Psychol., 46: 259-293. DOI: 10.1111/j.1744-6570.1993.tb00874.x

Whyte, W.H., 1956. The Organization Man. 1st Edn., University of Pennsylvania Press, Garden City, New York, ISBN-10: 0812218191, pp: 429.

$\mathrm{Wu}$, C.T., 2010. A study on the young students' intention to apply voluntary soldiers. Comb. Logistics Q., 20: 131-144. 